\title{
KENDALI SISTEM BIOREAKTOR KONTINYU
}

\section{CONTROL OF A CONTINUOUS BIOREACTOR}

\author{
Rudy Agustriyanto \\ Jurusan Teknik Kimia, Fakultas Teknik, Universitas Surabaya, Jl. Raya Kalirungkut, Surabaya, 60293, Indonesia \\ Email: rudy.agustriyanto@staff.ubaya.ac.id
}

\begin{abstract}
Abstrak
Tujuan dalam industri bioproses umumnya adalah memaksimalkan pertumbuhan mikroba dan / atau produksi beberapa senyawa yang dihasilkan oleh mikroorganisme. Untuk mencapai hal ini dengan cara yang efisien, maka diperlukan untuk menjaga lingkungan yang sesuai untuk mikroorganisme setiap saat. Tujuan utama penelitian ini adalah untuk menerapkan algoritma kendali PI (Proporsional integral) dan PID (Proporsional Integral Derivative) untuk suatu sistem bioproses. Kriteria Bode kemudian diterapkan untuk memeriksa kestabilan sistem diikuti dengan penentuan parameter pengendali menggunakan metode TLC (Tyreus-Luyben). Hasil simulasi lintas tertutup menunjukkan kinerja pengendalian yang dapat diterima.
\end{abstract}

Kata kunci: Bioproses; Bode; kendali PID; stabilitas

\begin{abstract}
The aim in an industrial bioprocess is commonly to maximize microbial growth and / or production of some compound produced by microorganisms. To achieve this in an efficient manner, it is necessary to maintain a suitable environment for the microorganisms at all times. The main objective of this research is to implement PI (Proportional Integral) and PID (Proportional Integral Derivative) control algorithm to the bioprocess system. The Bode criterion were then applied to check its stability followed by determining controller parameters using TLC method (Tyreus-Luyben). Closed loop simulation results were presented and it is found that TLC performance give acceptable results.
\end{abstract}

Keywords: Bioprocess; Bode; PID control; stability

\section{Pendahuluan}

Salah satu aspek penting dalam pengendalian bioproses adalah operasional real time yang stabil, tidak rentan terhadap berbagai gangguan, dekat dengan suatu keadaan tertentu atau profil yang diharapkan yaitu suatu kondisi operasi yang optimal [5]. Pengendalian bioproses sendiri dapat didefinisikan sebagai menyediakan lingkungan yang dekat optimal agar mikroorganisme dapat tumbuh berkembang biak dan menghasilkan produk yang diinginkan. Termasuk didalamnya menyediakan konsentrasi nutrisi yang tepat (misal karbon, nitrogen, oksigen, fosfor, sulfur, mineral), menghilangkan produk metabolik toksik (misal $\mathrm{CO}_{2}$ ) dan mengendalikan parameter seluler penting (misal $\mathrm{pH}$, suhu).

Model dinamika untuk suatu sistem bioreaktor telah tersedia [7]. Berdasarkan model dari Riggs dan Karim tersebut, Agustriyanto [1] mendapatkan fungsi hantar orde satu dalam domain Laplace,yang kemudian berhasil dikendalikan dengan pengendali PI [2]. Hasil simulasi lintas tertutup dengan pengendali PI yang disetel dengan metode sintesa langsung telah dipresentasikan [2].
Tujuan penelitian ini adalah menganalisa kestabilan sistem bioproses yang ditinjau dengan menggunakan kriteria kestabilan Bode, kemudian melakukan penyetelan pengendali dengan metode Tyreus-Luyben.

\section{Teori}

\section{Kriteria Kestabilan Bode}

Diagram Bode menunjukkan karakteristik response frekwensi suatu sistem $[4,6]$ dan terdiri atas sepasang plot yang menampilkan:

- Plot logaritmik rasio amplitudo $(A R)$ vs logaritmik frekwensi $(\omega)$

- Plot sudut fasa $(\varphi)$ vs logaritmik frekwensi $(\omega)$ Untuk menggunakan plot Bode, perlu dipahami definisi frekwensi cross-over $\left(\omega_{\mathrm{co}}\right)$ yaitu frekwensi dimana kelambatan fasa nya $-180^{\circ}$.

Kriteria kestabilan Bode menyatakan bahwa pada saat frekwensi cross-over, jika log modulus kurang dari $0 \mathrm{~dB}$, maka sistem adalah stabil.

Metode Penyetelan Pengendali TLC (TyreusLuyben) 
Segera setelah Bode plot tersedia, maka parameter pengendali dapat ditentukan menurut Tyreus-Luyben (TLC Tuning). Tabel 1 menunjukkan aturan penyetelan pengendali menurut TyreusLuyben. Tampak bahwa parameter pengendali adalah fungsi $K_{u}$ dan $P_{u}$, dimana:

$K_{u}=\frac{1}{A}=$ ultimate gain

$P_{u}=\frac{2 \pi}{\omega_{c o}}=$ ultimate period

$\mathrm{A}=$ harga amplitude rasio pada saat frekwensi

cross-over

Tabel 1. Aturan TLC untuk PI dan PID

\begin{tabular}{|c|c|c|c|}
\hline Pengendali & $\mathbf{K}_{\mathbf{c}}$ & $\boldsymbol{\tau}_{\mathbf{I}}$ & $\boldsymbol{\tau}_{\mathbf{D}}$ \\
\hline PI & $\frac{K_{u}}{3,2}$ & $2,2 P_{u}$ & \\
\hline PID & $\frac{K_{u}}{2,2}$ & $2,2 \boldsymbol{P}_{u}$ & $\frac{P_{u}}{6,3}$ \\
\hline
\end{tabular}

\section{Metodologi Penelitian}

\section{Sistem Bioreaktor}

Sistem bioreaktor yang dipelajari disini [7] ditunjukkan pada Gambar 1. Model dinamika untuk sistem ini adalah sebagai berikut:

$\frac{d x}{d t}=-\frac{F_{V}}{V} x+\mu_{\max } x$

$\frac{d S}{d t}=\frac{F_{V}}{V} S_{F}-\frac{F_{V}}{V} S-\frac{1}{Y_{x S}} \mu_{\max } x$

$\frac{d P}{d t}=-\frac{F_{V}}{V} P+\frac{1}{Y_{x P}} \mu_{\max } x$

Diasumsikan bahwa pertumbuhan sel mengikuti kinetika Monod dan sebagian besar substrat dikonsumsi oleh sel. Parameter dan variabel proses diberikan pada Tabel 2.

Pada industri, biasanya digunakan filter untuk semua aliran masuk dan keluar bioreaktor untuk menjaga kondisi steril, namun tidak ditunjukkan pada gambar di atas.

Umpan yang mengandung gula sebagai substrat $(S)$ dari jagung atau biji-bijian lainnya (seperti gandum, beras, barley dsb) dan garam nutrisi untuk mendukung pertumbuhan sel $(X)$. Sel $(X)$ mengkonsumsi substrat (S) dan menghasilkan produk $(P)$ dan $\mathrm{CO}_{2}$. Suatu blower udara memberikan oksigen kepada sel. Gas keluar terdiri atas nitrogen dari udara, oksigen yang tidak terkonsumsi, dan karbondioksida yang dihasilkan sel dari konsumsi gula. Konsentrasi sel diukur dengan suatu turbidimeter, konsentrasi substrat diukur dengan HPLC on-line.

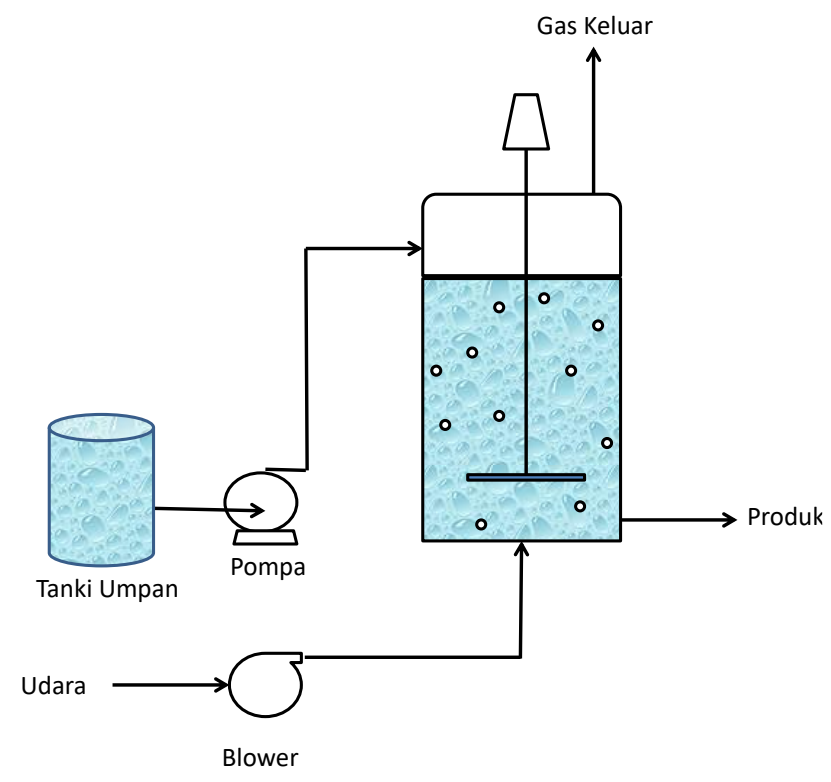

Gambar 1. Sistem Bioreaktor Kontinyu

Tabel 2. Parameter proses dan harga steady state

\begin{tabular}{|c|c|c|c|}
\hline Symbol & $\begin{array}{l}\text { Parameter } \\
\text { dan Variabel }\end{array}$ & Harga & Satuan \\
\hline$F_{v}$ & Laju alir umpan & 1000 & $\mathrm{~L} / \mathrm{j}$ \\
\hline$K_{s}$ & $\begin{array}{l}\text { Konstanta saturasi } \\
\text { Monod }\end{array}$ & 0,1 & $\mathrm{~g} / \mathrm{L}$ \\
\hline$P$ & $\begin{array}{l}\text { Konsentrasi produk } \\
\text { dalam reaktor }\end{array}$ & 1,25 & $\mathrm{~g} / \mathrm{L}$ \\
\hline$S$ & $\begin{array}{l}\text { Konsentrasi substrat } \\
\text { dalam reaktor }\end{array}$ & 25 & $\mathrm{~g} / \mathrm{L}$ \\
\hline$S_{F}$ & $\begin{array}{l}\text { Konsentrasi substrat } \\
\text { pada umpan }\end{array}$ & 50 & $\mathrm{~g} / \mathrm{L}$ \\
\hline$t$ & Waktu & & $\mathrm{h}$ \\
\hline V & Volume reaktor & 5000 & $\mathrm{~L}$ \\
\hline$x$ & $\begin{array}{c}\text { Konsentrasi sel dalam } \\
\text { reaktor }\end{array}$ & 0,25 & $\mathrm{~g} / \mathrm{L}$ \\
\hline$Y_{x P}$ & Yield faktor & 0,2 & $\begin{array}{l}\text { g-sel/g- } \\
\text { produk }\end{array}$ \\
\hline$Y_{x S}$ & Koefisien yield & 0,01 & $\begin{array}{l}\text { g-sel/g- } \\
\text { substrat }\end{array}$ \\
\hline$\mu_{\max }$ & $\begin{array}{l}\text { Laju pertumbuhan } \\
\text { spesifik maksimum }\end{array}$ & 0,2 & $j$ \\
\hline
\end{tabular}

\section{Fungsi Hantar Sistem Bioreaktor}

Studi dinamika dalam domain waktu memerlukan solusi langsung dari persamaan diferensial. Namun untuk keperluan analisis dan desain pengendalian, lebih disukai untuk mendapatkan fungsi hantar dalam domain Laplace.

Fungsi hantar untuk sistem tersebut di atas telah ditentukan sebelumnya [1] dengan 
menyelesaikan 3 persamaan differensial (Pers.4-6) dan memperhatikan parameter dan harga steady state pada Tabel 2 dengan menggunakan Differential Equation Editor (DEE) pada Matlab. Hasil simulasi kemudian diidentifikasi dengan menggunakan System Identification Toolbox.

Fungsi hantar sistem bioreaktor kontinyu tersebut adalah sebagai berikut:

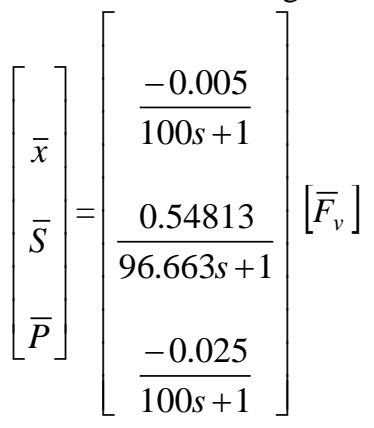

\section{Hasil dan Pembahasan}

Pada sistem ini, produk $(P)$ akan dikendalikan dengan memanipulasi laju alir umpan $(F v)$. Diasumsikan terjadi waktu tunda dari pengukuran konsentrasi produk sebesar 5 menit sehingga untuk keperluan pembuatan diagram Bode, fungsi hantar antara produk terhadap laju alir umpan menjadi sebagai berikut:

$\left[\frac{\bar{P}}{\bar{F}_{V}}\right]=\frac{-0.025}{100 s+1} e^{-5 s}$

Gambar 2 menunjukkan diagram Bode untuk sistem bioreaktor kontinyu. Dari diagram Bode diperoleh harga frekwensi cross-over sebesar 0,944 dan amplitudo sebesar 0,000266 pada saat frekwensi cross-over, sehingga harga ultimate gain dan ultimate period dapat ditentukan:

$K_{u}=3759$

$P_{u}=6,6599$

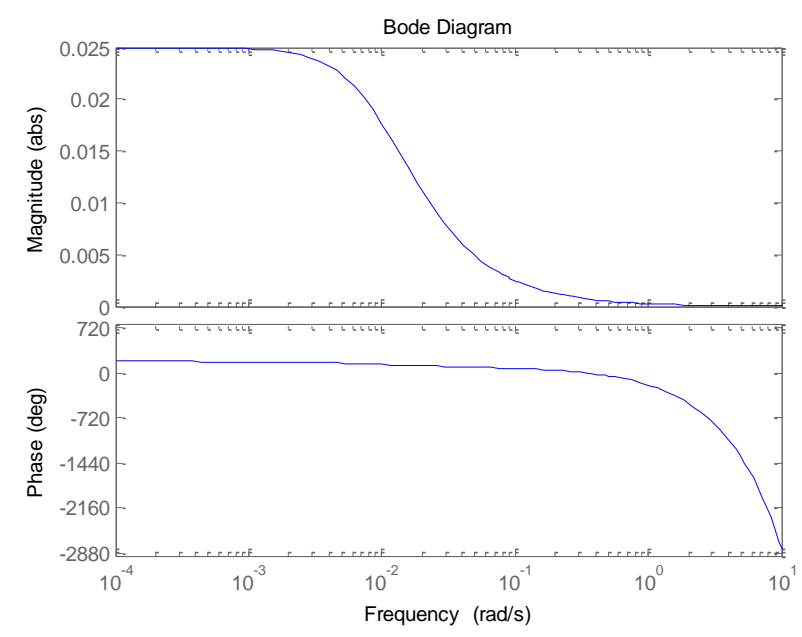

Gambar 2. Diagram Bode
Sesuai kriteria kestabilan Bode, sistem adalah stabil karena harga amplitudo rasio kurang dari 1 (log modulus kurang dari nol) pada saat frekwensi cross over. Harga parameter pengendali ditunjukkan pada Tabel 3, yang dihitung menurut Tabel 1 .

Tabel 3. Harga parameter pengendali

\begin{tabular}{|c|c|c|c|}
\hline Pengendali & $\mathbf{K}_{\mathbf{c}}$ & $\boldsymbol{\tau}_{\mathbf{I}}$ & $\boldsymbol{\tau}_{\mathbf{D}}$ \\
\hline PI & -1175 & 14,65 & \\
\hline PID & -1709 & 14,65 & 1,06 \\
\hline
\end{tabular}

Gambar 3 menunjukkan plot konsentrasi (P) vs waktu untuk pengendali PI dan PID yang dibandingkan dengan perubahan set point yang dilakukan, yaitu dari kondisi steady state $(1,25 \mathrm{~g} / \mathrm{L})$ diubah harganya menjadi $1,24 \mathrm{~g} / \mathrm{L}$ pada saat $\mathrm{t}=0$ (mula-mula) kemudian pada saat $\mathrm{t}=200$ dinaikkan menjadi 1,225 g/L dan akhirnya kembali ke 1,25 g/L pada saat $\mathrm{t}=300$.

Tampak dari Gambar 3, bahwa sistem kendali yang disetel dengan metode TLC memiliki kinerja yang memuaskan baik PI maupun PID, dan memberikan hasil yang mirip. Variabel yang dikendalikan (P) mampu meresponse dengan baik terhadap perubahan set point (fungsi servo). Begitu pula, dari Gambar 4 tampak bahwa profile variable yang tidak dikendalikan (sel dan substrat) berubah dimana kinerja PI dan PID hampir sama sehingga plot PI dan PID seperti segaris dan tidak tampak perbedaaannya.

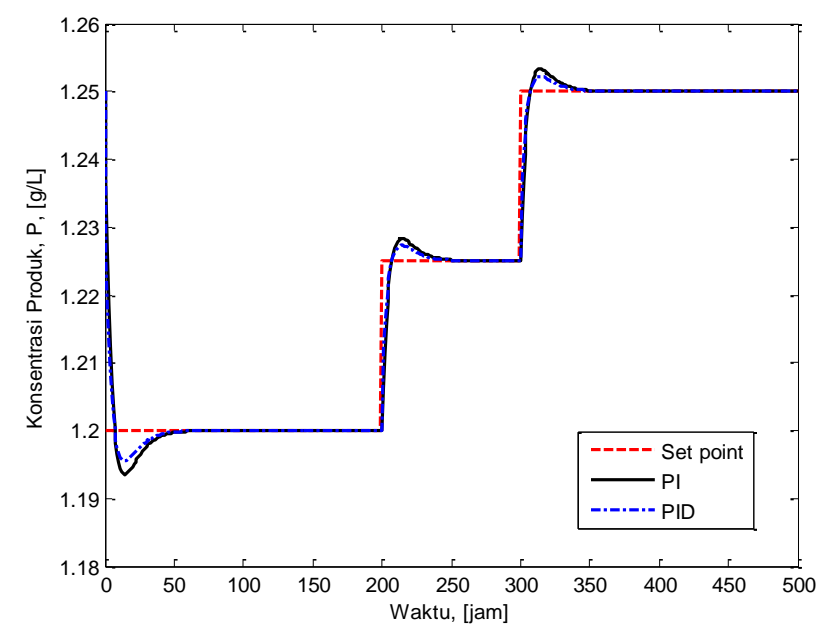

Gambar 3. Plot konsentrasi produk (P) vs waktu untuk pengendali PI dan PID 

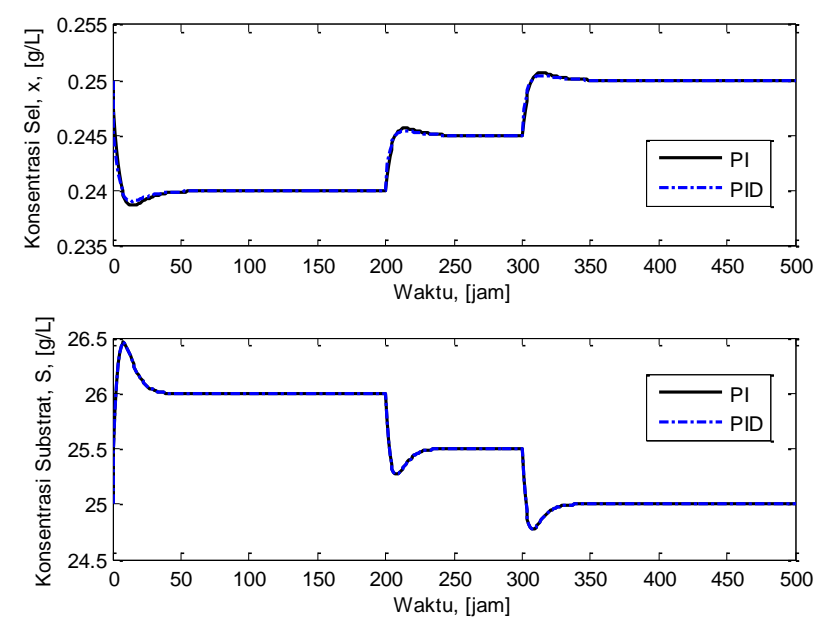

Gambar 4. Plot konsentrasi sel (x) dan substrat (S) vs waktu

\section{Kesimpulan}

Hasil analisa kestabilan Bode menyatakan bahwa sistem yang dipelajari adalah sistem yang stabil. Untuk memudahkan penyetelan pengendali, digunakan asumsi waktu tunda sebesar 5 menit pada fungsi hantar karena sistem orde satu tanpa fungsi hantar akan kesulitan dalam mendapatkan frekwensi cross-over. Penyetelan pengendali dengan metode TLC telah dilakukan untuk tipe PI dan PID dan memberikan kinerja yang baik (Gambar 3 dan 4).

\section{Ucapan Terimakasih}

Penulis mengucapkan terima kasih kepada Universitas Surabaya.

\section{Daftar Pustaka}

[1] Agustriyanto, R., Simulation of Continuous Bio-Reactor, Proceedings of the International Conference of Chemical Engineering on Science and Applications (The 8th Chesa 2015), 9-11 September 2015, Banda Aceh Indonesia.

[2] Agustriyanto, R., (2016), PI Control of a Continuous Bio-Reactor, Proceedings of the 6th Annual International Conference (AIC 2016), October 4-6, 2016, Banda Aceh Indonesia.

[3] Alford, J.S., (2006), Bioprocess Control: Advances and Challenges, Computers and Chemical Engineering, 30 (10-12), 1464-1475.

[4] Coughanowr D R, (1991), Process Systems Analysis and Control, McGraw Hill, New York.

[5] Dochain D, (2008), Bioprocess Control, John Wiley and Sons, Inc.
[6] Luyben, W.L., (1996), Process Modeling, Simulation and Control for Chemical Engineers, McGraw Hill, New York.

[7] Riggs J B, Karim M N, (2006), Chemical and Bioprocess Control, Pearson Prentice Hall.

[8] Tomas B. Co, 2017. Ziegler-Nichols Method. <http://www.chem.mtu.edu/ tbco/cm416/zn.ht ml> diakses pada 5 January 2017. 